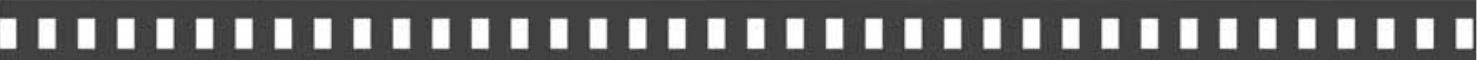

\author{
Resenha: Um espelho que precisa \\ ser quebrado na Comunicação
}

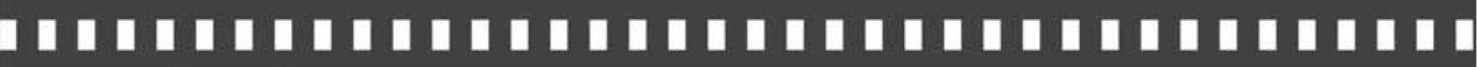

\author{
Emerson dos Santos Dias
}




\section{Um espelho que precisa ser quebrado na Comunicação}

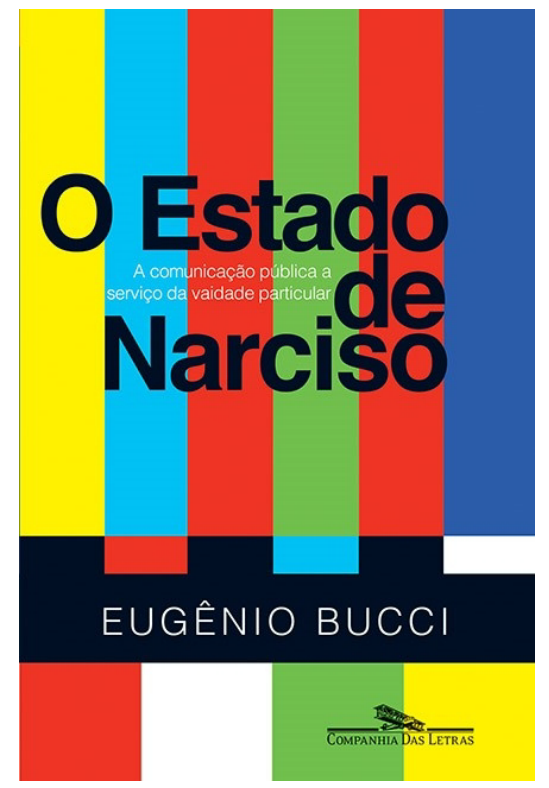

BUCCI, Eugênio. O Estado de Narciso: A comunicação pública a serviço da vaidade particular. São Paulo:

Companhia das Letras, 2015

Emerson dos Santos Dias *

Com "O Estado de Narciso: a comunicação pública a serviço da vaidade particular" (Companhia das Letras), o jornalista, professor, pesquisador e escritor Eugênio Bucci reafirma sua trajetória como um dos raros profissionais que lançam luz neste ambiente nebuloso da informação pública.

* Jornalista e professor de Comunicação Social, doutorando em Comunicação pela UERJ, mestre em Ciências Sociais pela UEL e especialização em História e Sociedade pela UEM. 
Entre embates extremistas e maniqueístas que transbordam das redes sociais digitais e invadem ruas e avenidas com bandeiras destoantes dos desejos racionais até então guardadas no baú da História recente (como o pedido de nova intervenção militar, só para ficar na pior reivindicação registrada de norte a sul deste país durante o ano em questão), uma batalha de forças envolvendo os bastidores das mídias tradicionais se faz aparentemente difusa, sem que a sociedade participe ou se dê conta das artimanhas de aparelhamento da comunicação pública do governo, seja ele municipal, estadual ou federal.

Para Bucci, o ambiente comunicacional atual "transforma os direitos políticos em objetos de consumo ou objetos de adoração. Estimula o cidadão a não mais se ver como fonte genuína de poder" (BUCCI, 2015, p. 29). A partir de experiências em três ambientes distintos - na academia, no mercado privado e em mídias públicas o autor trata da transformação do ato de informar, publicizar, expor de forma transparente as ações, propostas e problemas de interesse público em pura propaganda e autopromoção oficial, a tal ponto de as campanhas exibirem logomarcas e frases de efeito típicas do ramo publicitário comercial.

O próprio relacionamento entre órgãos públicos e imprensa sob os aspectos legais, envolvendo editais e campanhas oficiais, é exposto como um intrincado jogo de interdependência, atração e repulsa envolvendo a malha midiática brasileira, já que haveria uma "resistência difusa de milhares de jornais e emissoras de rádio, principalmente os de médio porte, que se tornaram dependentes dessa fonte de recursos" (p. 35), perpetuando o jogo de interesses particulares em detrimento do interesse da sociedade.

O livro é dividido em cinco grandes partes que se entrecruzam e fazem remissão umas às outras. Antes delas, a introdução do texto ambienta as questões acima, mostrando-se um tanto quanto carregada de aparente ressentimento, decorrente - talvez - da experiência frustrada de tentar mudar procedimentos já engessados 
neste setor. Bucci foi presidente da extinta Radiobrás entre 2003 e 2007, estatal cujo espólio foi absorvido pela Empresa Brasil de Comunicação ao final de 2007 por meio de Medida Provisória, criando assim a Empresa Brasil de Comunicação (EBC), empresa que deveria sintetizar a comunicação pública no país. O pesquisador expõe, inclusive, vários momentos desta experiência no comando de uma rede de comunicação que deveria ser pública.

Felizmente, a vivência acadêmica e o extenso currículo do pesquisador logo se evidenciam na primeira parte, quando trata de organizar os argumentos e apresentar conceitos de comunicação pública. Com base em autores e títulos já conhecidos, principalmente os trabalhos organizados por Jorge Duarte ("Comunicação Pública: Estado, Mercado, Sociedade e Interesse Público”, Atlas, 2012), Bucci discorre sobre os elementos que deveriam compor a informação envolvendo o Estado, mídia e sociedade.

Assim como nas pesquisas de doutorado deste resenhista envolvendo Jornalismo Público, Bucci também encontra vozes diversas no ambiente acadêmico que buscam enquadrar a comunicação pública das mais variadas formas, desde o trabalho das assessorias governamentais até a disseminação de informações por meios de Organizações Não Governamentais (ONGs) e comunitárias. Há enquadramentos sob o viés de planejamento estratégico de comunicação, amparado pelas Relações Públicas e por autores como Mariângela Haswani e o colombiano Jamarillo López, até processos que enveredam pelas instituições estatais mas que se consolidam no espaço público, efetivando os acessos e a construção dos interesses coletivos (culturais, políticos e econômicos), como afirmam pesquisadores essenciais como Pierre Zémor e Elizabeth Brandão.

Como o próprio Bucci afirma ser "um objeto que está em toda a parte, como Deus ou o diabo" (p. 41), uma ótima maneira de diminuir as distâncias e apresentar bases mais sólidas para este conceito foi recorrer à Constituição, principalmente os artigos $5^{\circ}$ 
("todos têm direito a receber dos órgãos públicos informações de seu interesse particular, ou de interesse coletivo ou geral") e o 37, que trata especificamente do processo de publicização de serviços, ações e projetos dos órgãos públicos, "que deverá ter caráter educativo, informativo ou de orientação social, dela não podendo constar nomes, símbolos ou imagens que caracterizam promoção pessoal de autoridades ou de servidores públicos".

Exatamente a partir das determinações legais que a crítica do livro se estabelece: "No Brasil, a impessoalidade é uma norma constitucional - e é ela que nos ajuda a entender por que a comunicação pública não pode incorrer no partidarismo" (p. 68). No entender de Bucci, sob comprovadas evidências apresentadas como exemplos, gastos milionários deturparam o "tornar público" e o transformaram em objeto de consumo para o cidadão-consumidor.

Antes de aprofundar-se neste ambiente onde $\mathrm{o}$ ato de publicizar foi substituído pelo marketing, o autor utiliza os capítulos dois e três para tratar dos limites e possibilidades dos veículos públicos de comunicação. Discorre sobre os contornos ainda recentes dos nove anos da $\mathrm{EBC}$ (se comparado aos 90 anos da BBC inglesa, por exemplo), mostrando dificuldades que também envolvem o cidadão como espectador ativo, a começar pelas relações de dependência financeira entre o público e o privado. Alemanha, Suécia, Dinamarca e Finlândia contam com empresas públicas de comunicação $90 \%$ subsidiadas pelo pagamento de taxas anuais de cada família que possui rádio e TV em casa. Na Inglaterra, as residências recebem todos os anos a cobrança de 145 libras que garantirão subsídios à gigantesca produção da BBC (p. 89-90).

Para o brasileiro, parece ser impensável pagar para ter uma programação em canal aberto porque há décadas ele usufrui de programas aparentemente gratuitos (embora ele esteja "vendendo", sem saber, a sua audiência). Aqui, a questão é mais que financeira: os veículos de comunicação no Brasil não priorizaram aquilo que está na Constituição e também não construíram junto à sociedade a 
percepção de que as concessões de radiodifusão são públicas e, portanto, pertencentes aos cidadãos tanto quanto uma praça ou um posto de saúde.

Bucci segue ainda tratando de exemplos nacionais, como a TV Cultura de São Paulo e a TV Brasil (braço televisivo da EBC), expondo pontos positivos e negativos, criticando outra dependência - a estética - em relação às emissoras comerciais. Para isso, o autor sugere cinco bandeiras que deveriam ser referências na produção audiovisual pública (p. 119-124), dentre elas "desmontar a oferta do gozo pré-fabricado" e "emancipar em lugar de vender", seja a programação, os funcionários e principalmente os telespectadores. "A televisão pública não quer público cativo como a televisão comercial. (...) não tem a missão de ser cativeiro, de prender os olhos do telespectador, mas de atuar como fator de emancipação" (p. 123).

Por fim, critica e pede o fim d'A Voz do Brasil, que "virou sinônimo de propaganda chapa-branca, a serviço de instituições envelhecidas, insensíveis e distantes" (p. 150), antes de adentrar as partes quatro e cinco, onde insere também críticas às propagandas oficiais - "proselitismo e desinformação" - dos governos em suas variadas instâncias.

Usando dados e reportagens do período pré-eleições presidenciais, cita exemplos de prefeituras diversas (cujos orçamentos publicitários aumentaram em 400\% em cinco anos), do finado candidato Eduardo Campos ("Campos irá gastar R\$ 100 milhões em propaganda em PE”, publicou a Folha de São Paulo em março de 2014) e, claro, do governo federal petista e da gestão tucana em Minas Gerais.

Nos dois governos de Luiz Inácio Lula da Silva, entre 2003 e 2010, o slogan "Brasil, um país de todos" cumpriu a nobre missão de funcionar como sinônimo de "governo Lula". No governo Dilma, foi a vez do "País rico é país sem pobreza". (...) Há variantes mais ou menos criativas. Em Minas Gerais, a expressão "choque de gestão" foi de tal maneira associada à identidade de Aécio Neves que virou uma marca registrada tanto dele quanto do seu governo (BUCCI, 2015, p. 167). 
As condições atuais da comunicação pública ferem o artigo 37 da Constituição, que prevê impessoalidade e ausência de referências que identifiquem esta ou aquela pessoa no ato de informar sobre um projeto ou obra em andamento. "Não é mais a comunicação que se presta a tornar conhecidas as obras realizadas. São as obras que, se necessárias ao projeto de comunicação, ilustram e dão materialidade à imagem que a autoridade pretende forjar para si mesma” (p. 181).

Somente a comunicação pública erra ao se comportar como mídia privada? Bucci utiliza uma ponderação pessimista ao dizer que a doutrina governamental (novamente em qualquer âmbito: municipal, estadual ou federal) vê a imprensa como inimiga por "bater" com frequência quem está no poder e usa este argumento para oferecer "uma verdade" distorcida para compensar "a verdade da mídia privada”. Assim, “a 'verdade' dos fatos seria uma espécie de média aritmética entre duas distorções deliberadas" (p. 199).

Para nós, comunicadores sociais e jornalistas, tais elementos a serem destrinchados demonstram que a guerra midiática se apresenta em diversos níveis e nichos, seja o internacional, o partidário, corporativo, comercial ou ideológico. São distorções presentes em qualquer ambiente comunicacional, mas que se mostram mais visíveis nos bastidores do poder.

Na quinta e última parte, Bucci trata da experiência que teve como presidente da Radiobrás, antecipando-se ao questionamento lógico dos leitores. Aqui surgem o reconhecimento de algumas derrotas, especialmente em relação à Voz do Brasil.

A mudança que acreditávamos conduzir tinha a característica de ser cuidadosa, vagarosa e prudente. Talvez em demasia. O oficialismo essencial continuava lá, imerso na cultura, na inércia da organização. Continuava inabalável, apesar de nós. Eu mesmo negociava diariamente com ele. Cedia a ele. Não bastasse a Voz do Brasil, criei pessoalmente um novo programa de rádio [Café com o Presidente] para o presidente da república. (BUCCI, 2015, p. 192).

Sendo assim, não haveria saída neste entrave midiático no qual 
está inserido a comunicação pública? A solução aparente está na reformulação das empresas públicas a partir de conselhos mais ativos e profissionais mais engajados e com visão jornalística entendida efetivamente como uma função pública, mesmo aqueles que seguem na mídia privada.

Bucci questiona o entendimento de imprensa brasileira como um oligopólio composto por empresas de não mais que sete famílias. $\mathrm{O}$ pesquisador acredita que imprensa deve ser entendida como mediadora da construção histórica da democracia ao mesmo tempo em que por esta foi construída. Sendo assim, o ideal de imprensa livre deve estar presente em qualquer redação ou assessoria, em um site ou na comunicação de um movimento social.

Desta instituição não estatal, que podemos definir como imprensa, fazem parte não apenas os grandes diários ou as redes continentais de TV, mas cada blog, cada pequena emissora, cada iniciativa de comunicação que esteja amparadas por esses direitos (liberdade de expressão e direito à informação) e que, pelo simples fato de existir, concorre para expandi-los. (BUCCI, 2015, p. 203).

É emblemático que o último subitem se chame "Que tal um pouco de “jornalismo jornalístico'?”, pois demonstra que o exercício desta profissão já se constitui como função pública e social.

A conclusão do livro utiliza a crise hídrica que o estado de São Paulo enfrentou e a maneira deturpada com que o governo optou por iniciar uma campanha que deveria deixar claras as condições enfrentadas. Foram, segundo Bucci, estratégias para "culpar condições climáticas" e manter a imagem do governo de vítima às vésperas das eleições em 2014. Imagem esta, mantida mais uma vez por marketing rasteiro travestido de comunicação pública. "Haja cinismo. Os que mais reclamam não fazem nada para mudar o marco regulatório dos meios de comunicação no Brasil” (p. 222).

Após afirmar isso, Bucci encerra o texto com sugestão de seis medidas para "sepultar o patrimonialismo que usurpa a comunicação pública” (p. 223-225). São elas, aqui brevemente resumidas: 
eliminar os gastos da publicidade oficial dos governos; impedir a administração direta de veicular qualquer mensagem alusiva a causas ideológicas e barrar slogans e logotipos que identifiquem a gestão; retirar das mídias comerciais a publicidade legal (editais, balanços, etc.) e colocá-las em sites oficiais; dotar todas as empresas e órgãos públicos, que utilizem mecanismos de comunicação social, de conselhos efetivamente independentes; extinguir a publicidade comercial nas emissoras públicas; acabar de vez com a obrigatoriedade d'A Voz do Brasil.

$\mathrm{O}$ autor destaca que, como tais resoluções precisam passar pelas mãos dos políticos (Executivo e Legislativo federal, estaduais e municipais), cabe à sociedade conhecer, pressionar e vigiar ações neste segmento, pois são eles que "elegem os beneficiários dessa usurpação reiterada e consistente da comunicação pública. Se os cidadãos não derem o grito de basta, ninguém mais fará isso por eles". É uma convocação para quebrarmos o espelho de Narciso que está nas mãos do Estado e mostrar a ele a realidade por meio dos nossos olhos. 